\title{
Compound heterozygous recessive thalassemia intermedia unusual presentation: a case report
}

\author{
Rugmini K $\mathbf{1}^{1}$ Divya $\mathbf{N}^{2}$ \\ ${ }^{1}$ Dr Rugmini Kamalammal, Associate Professor of Pediatrics, ${ }^{2}$ Dr Divya Narayanan Kutty, Postgraduate, Department of \\ Pediatrics; both authors are affiliated with Adichunchanagiri, Institute of Medical Sciences, B G Nagara, Nagamangala \\ Taluk, Mandya District, Karnataka, India.
}

Address for Correspondence: Dr Divya Narayanan Kutty, Email: dichu5985@gmail.com

\begin{abstract}
About $3 \%$ of the world's population carry $\beta$-Thalassemia genes. More than 200 mutations have been described, majority are point mutations and also some rare cases of gene deletion (17 deletions) have been reported. Those with Compound heterozygous inheritance present with two different mild $\beta$-thalassemia alleles and borderline RBC indices. We report a pre-adolescent girl with $\beta$-thalassemia intermedia who became transfusion dependent and developed alloimmunization.

This case is presented to highlight the fact that compound heterozygousity is a possible entity in a non-consanginous parentage and may present with subtle clinical features and minimal laboratory evidence and those children who start receiving transfusion later in their life are more prone for alloimmunization.
\end{abstract}

Keywords: Thalassemia intermedia, Alloimmunization, Compound heterozygousity

\section{Introduction}

About 3\% (150 million) of the world's population carry $\beta$-Thalassemia genes [1]. The annual incidence of symptomatic cases of beta-thalassemia is estimated at $1 / 100,000$ while the frequency of carrier state has been $270 /$ million [2]. $\beta$ - thalassemia is mainly distributed in the Mediterannean belt including India (35 million are carriers) and Pakistan [3]. More than 200 mutations are seen, majority being point mutations, of which 28 are seen in Indian patients [4].

Deletions accounts for 17 mutations [1]. The 619-bp deletion, removing the 3 ' end of the $\beta$-globin gene is relatively common in India (Sind and Punjab populations) [4]. Thalassemia intermedia is most commonly associated with a homozygous state for two $\beta$-thalassemia alleles or rarely a compound heterozygous state [1]. Compound heterozygotes present with mild $\beta$-thalassemia alleles and borderline $\mathrm{RBC}$ indices. Regular transfusions becomes necessary with increasing age that occurs at $\mathrm{Hb}$ levels below $7 \mathrm{gm} \%$ with stunted growth, poor general condition, skeletal deformities and infections [5].

Delaying the age of transfusion increases the risk of developing alloimmunisation [6]. The pathogenesis of alloimmunisation has been attributed to hidden antigens from peripheral red blood cell fragmentation [1]. The increased mortality in thalassemia is attributed to pulmonary hypertension and hemochromatosis in cardiac muscle.

\section{Case Report}

A 10 year old pre-adolescent girl born to non-consanginous parentage presented with history of palpitations, exertional dyspnea since 6 months and acute onset of fever. Examination showed severe pallor, mild icterus and maxillary prominence. Systemic examination revealed hepatosplenomegaly with decreased breath sounds in the right infrascapular and infraaxillary area with a dull note on percussion. Hb was $4 \mathrm{gm} \%$ with normal reticulocyte count, MCV-66.3fl, MCH20.4pg, MCHC-30.8g/dl and RDW-14. Peripheral smear showed anisocytosis, scanty RBCs with microcytic

Manuscript received: $4^{\text {th }}$ October 2016

Reviewed: $15^{\text {th }}$ October 2016

Author Corrected; $25^{\text {th }}$ October 2016

Accepted for Publication: $7^{\text {th }}$ November 2016 
hypochromic, fragmented RBCs, target cells, tear drop cells, polychromatic cells and basophilic stippling all suggestive of a haemolytic anemia. Direct Coomb's test initially was negative and osmotic fragility test also was negative.

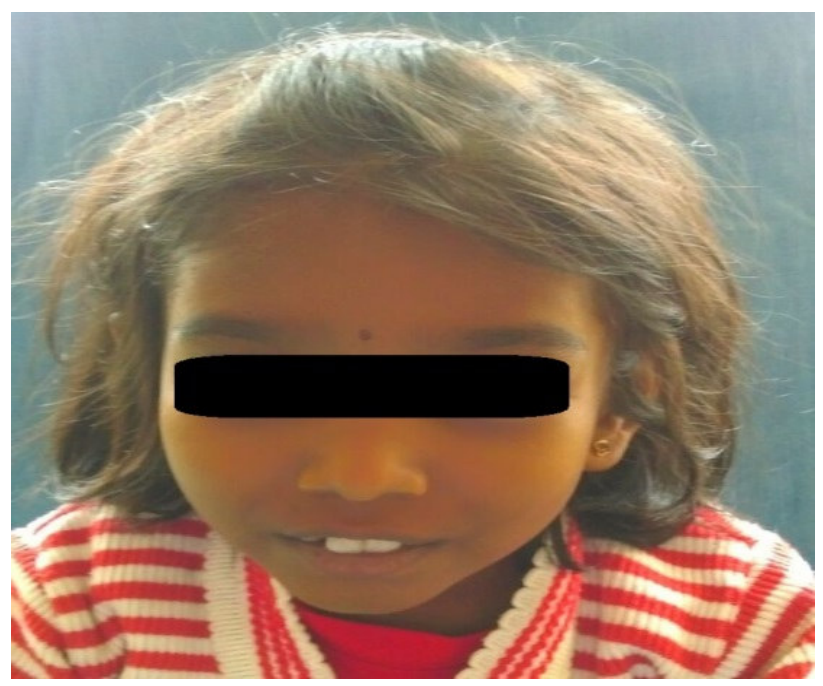

Figure-1: Child with pallor, icterus and maxillary prominence

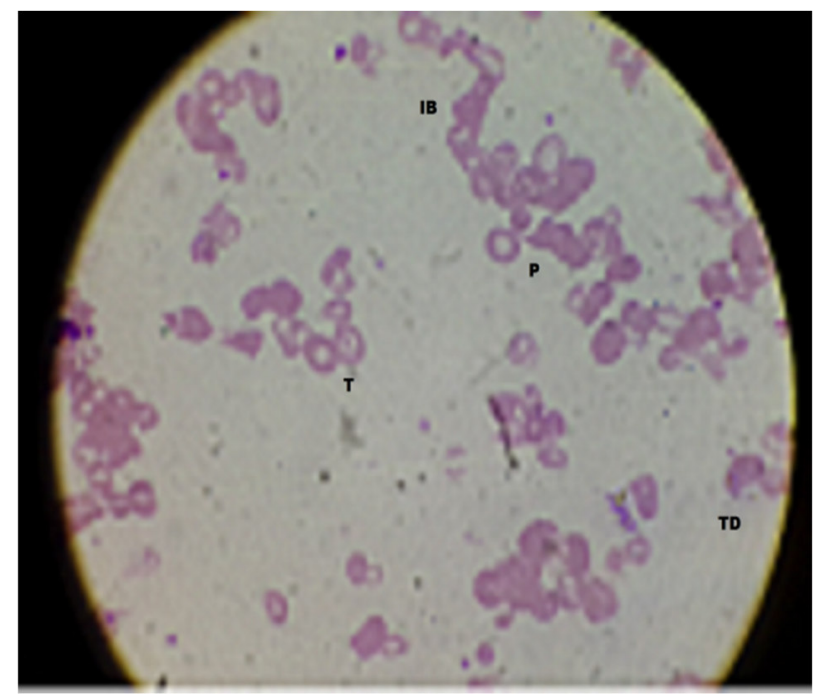

Figure-2: Peripheral smear showing microcytic hypochromic picture with tear drop cells, target cells, inclusion bodies

Meanwhile both parents were found to be $\beta$-thalassemia trait. Mother showed elevation of $\mathrm{HbA2}(6.6 \%)$ and $\mathrm{HbF}(7.5 \%)$ and father had $\mathrm{HbA} 2(4.8 \%), \operatorname{HbF}(1.1 \%)$.

She required $4 \mathrm{PRBC}$ transfusions to reach a $\mathrm{Hb}$ of $9 \mathrm{gm} \%$. Child was started on ATT (RNTCP-CAT 1) considering chest $\mathrm{X}$-ray showing persistent opacity in the right lower zone even after antibiotic therapy, strong contact history and positive Mantoux test. Child was discharged on day 18 but readmitted within 2 weeks with cardiac failure and $\mathrm{Hb} 2 \mathrm{gm} \%$. At this admission, reticulocyte count was low and the bone marrow showed erythroid hyperplasia with normal myeloid and megakaryocyte precursors. DCT was positive and repeated chest x-ray showed some clearing of the pulmonary opacity. As the child was in failure, she was transfused again.

She was referred for further care to another tertiary centre. Her evaluation there showed persistence of anemia with DCT being positive. The possibility of auto or alloantibodies was considered and she was started on methylprednisolone and 
ATT continued. CT chest and abdomen was done to rule out secondary causes of autoantibodies. ECHO was suggestive of pulmonary hypertension (systolic $>30$ and diastolic $>35$ ). In view of the parents being beta thalassemia trait, a diagnosis of $\beta$-thalassemia intermedia was considered and she was started on iron chelation therapy, hydroxyurea and Prednisolone with a plan to treat her based on thalassemia intermedia guidelines. The child however continued to be transfusion dependent with very low $\mathrm{Hb}$ and went into congestive cardiac failure. Repeated attempts at transfusion were difficult due to inability to cross match packed cell units. Despite steroid therapy and attempts to get her adequate packed cell transfusions, she succumbed to severe anemia and congestive cardiac failure. Mutation studies on this child could not be sent.

Her 12 year old sister was screened. Her evaluation showed a stunting, pallor and splenomegaly. However she had been asymptomatic and never received any transfusions. Her HPLC showed possibilities of a beta thalassemia intermedia [HbF $90.2 \%$, HbA2 5.3\%] or a delta beta thalassemia. She is on follow up and doing well.

\section{Discussion}

BT intermedia is caused by minor and/or silent mutations in the $H B B$ gene (11p15.5) encoding the beta-chains of hemoglobin $(\mathrm{Hb})$, in the homozygous or compound heterozygous state [4].

This case was probably a silent $\beta$-thalassemia, compound heterozygous $\beta^{+} / \mathrm{A}$ as evidenced by the late presentation and microcytosis. Compound heterozygousity is suggested as the child was born out of a non-consanginous marriage and both parents were having 2 different patterns of electrophoresis. Here, the mother has an elevated value of $\mathrm{HbA} 2$ of $6.6 \%$. ( $\mathrm{HbA} 2$ $>5 \%$ suggestive of a deletion) [1] and father had $\mathrm{HbA} 2$ of $4.8 \%$ not suggestive of a deletion. Tuberculosis would have added on to the hemolysis.

BT intermedia encompasses a wide clinical spectrum with severe cases presenting between 2-6 years of age with anemia and features of extramedullary erythropoiesis and minor ones presenting as asymptomatic to features of anemia [7]. Cardiac involvement may also occur due to high-output state and pulmonary hypertension.

Repeated transfusions caused the alloimmunisation as evidenced by the conversion of negative DCT to positivity. Transfusion requirement at the later age would have caused the alloimmunisation [6]. Alloimmunization further complicates the transfusion therapy because of the difficulty in getting compatible blood, increased incidence of allo and autoantibody development, delayed haemolytic transfusion reaction (DHTR) and hyperhaemolysis syndrome. 5-30\% rate of alloimmunisation has been reported in thalassaemia patients, anti $\mathrm{E}$ and anti $\mathrm{c}$ being the commonest alloantibodies responsible. Extended phenotype matched, leucodepleted red cell transfusion is recommended in prevention of alloimmunization [8]
The etiology of pulmonary hypertension is attributed to a complex interaction of platelets, the coagulation system, erythrocytes, endothelial cells, inflammatory and vascular mediators.

The hemolysis process disables the arginine-NO pathway through the simultaneous release of erythrocyte arginase and cell-free NO which leads to anaemia, a chronic hypoxic state.

Due to repeated vasoconstriction, endothelial cell injury, smooth muscle proliferation, and obliterative vasculopathy develops leading to pulmonary hypertension. Iron overload can also be a contributing factor [9].

The child required repeated transfusions inspite of steroid therapy due to severe anaemia and poor cardiac status. To conclude, Compound heterozygous inheritance is rare in beta thalassemia and most cases do not present until adolescent period requiring transfusions. Transfusions at a later age carries risk of alloimmunisation. Hence timely diagnosis and treatment aid in the health of the child.

Funding: Nil, Conflict of interest: Nil

Permission from IRB: Yes

\section{References}

1. Borgna-Pignatti C, Galanello R. Thalassemias and related disorders: Quantitative disorders of hemoglobin synthesis. In: Greer JP, Rodgers GM, Paraskevas F, Foerster J, Lukens JN, Glader B, editors. Wintrobe's Clinical Hematology. 13th ed. Philadelphia: Lippincott Williams and Wilkins; 2014. p. 862-913.

2. Sarnaik AS. Thalassemia and Related Hemoglobinopathies. Indian J Pediatr. 2005; 72(4):319-24. 
3. Christopher AF, Kumari A, Chaudhary S, Hora S, Ali $\mathrm{Z}$, Agrawal SC. Unique pattern of mutations in $\beta$ thalassemia patients in Western Uttar Pradesh. Indian J Hum Genet. 2013 Apr;19(2):207-12. doi: 10. 4103/0971-6866.116119.

4. Grow et al. Beta thalassemia in India: current status and the challenges ahead. Int J Pharm Sci. 2014; 6(4):28-33.

5. Musallam KM, Taher AT, Rachmilewitz EA. $\beta$ thalassemia intermedia: a clinical perspective. Cold Spring Harb Perspect Med. 2012 Jul;2(7):a013482. doi: 10.1101/cshperspect.a013482.

6. Sadeghian MH, Keramati MR, Badiei Z, et al. Alloimmunization among transfusion-dependent thalassemia patients. Asian Journal of Transfusion Science. 2009;3(2):95-98.

7. Cappellini MD, Cohen A, Eleftheriou A, et al. Guidelines for the Clinical Management of Thalassaemia. 2nd Revised ed. Nicosia (CY): Thalassaemia International Federation; 2008.

8. Chaudhari CN. Red Cell Alloantibodies in Multiple Transfused Thalassaemia Patients. Med J Armed Forces India. 2011 Jan;67(1):34-7. doi: 10.1016/S0377-1237 (11)80008-0. Epub 2011 Jul 21.

9. Morris CR, Vichinsky EP. Pulmonary hypertension in thalassemia. Ann N Y Acad Sci. 2010 Aug; 1202:205-13. doi: 10.1111/j.1749-6632. 2010.05580.x.

\section{How to cite this article?}

Rugmini K, Divya N. Compound heterozygous recessive thalassemia intermedia unusual presentation: a case report. Int.J Pediatr Res. 2016;3(11):798-801.doi:10.17511/ijpr.2016.i11.04. 